\title{
EFFECT OF POUNDING ON MULTISTOREY ADJACENT ELASTIC REINFORCED CONCRETE BUILDINGS UNDER EARTHQUAKE EXCITATION
}

\author{
Prof. V. P. Kulkarni \\ Professor, Department of Civil Engineering \\ Amrutvahini college of Engineering, \\ Amrutnagar (422608), Sangamner, India
}

\begin{abstract}
When two buildings are placed too close to each other without adequate seismic gap then during strong ground motion it may lead to pounding. When there is collision of two buildings which are of different dynamic characteristics is called as seismic pounding. Normally seismic gap element is used to assess the pounding force, many software FE packages are capable to carry out the seismic analysis of building subjected to pounding. For seismic pounding analysis the only nonlinear step by step integration method such as Newmark Beta, Wilson Theta method is applicable. In the present study, Experimental investigation and analytical investigation of seismic pounding effect is studied. A small scale $\mathbf{G + 1}$ steel building is consider for study over shake table. The same model is also prepared in SAP 2000NL software for seismic analysis. Modelling and analysis of adjacent buildings has been carried out with specific storey height and varying separation distance. Then on linear time history analysis is performed for specific adjacent building model. The digital data acquisition system with displacement/velocity/acceleration sensors are used in shake table study to measure the displacement/velocity/acceleration at each floor levels. It is observed that the experimental results and software results are in good agreement. In presence of pounding the acceleration at the floor levels are significantly increases which results into the large displacements at the floor levels. Which may also increases the base shear, base moments of the structures. In individual members of adjacent structure, the axial force, shear force and bending moments may also increase due to the effect of pounding. The amplification of internal force quantity is depend upon the seismic gap and adjacent building structural properties.
\end{abstract}

Keywords - Seismic pounding, shake table with digital data acquisition system, nonlinear step by step integration time history method

\author{
Mr. B. A. Sapike \\ ME, Structure (Civil Engineering) \\ Amrutvahini college of Engineering \\ Amrutnagar (422608), Sangamner, India
}

\section{INTRODUCTION}

Building collision commonly called pounding occurs during an earthquake when due to their different dynamic characteristics adjacent building vibrates out of phase and there is insufficient separation distance between them. Investigations of past and recent earthquake damage have illustrated that the building structures are vulnerable to severe damage and collapse during moderate to strong ground motion. An earthquake with a magnitude of six is capable of causing severe damages of engineered buildings, bridges, industrial and port facilities as well as giving rise to great economic losses. Several destructive earthquakes have hit India and nearby countries in both historical and recent times. Pounding between closely spaced building structures can be a serious hazard in seismically active areas.

The significant pounding was observed at sites over $90 \mathrm{~km}$ from the epicenter thus indicating the possible catastrophic damage that may occur during future earthquakes having closer epicenters. Pounding of adjacent buildings could have worse damage as adjacent buildings with different dynamic characteristics which vibrate out of phase and there is insufficient separation distance or energy dissipation system to accommodate the relative motions of adjacent buildings.

\section{EXPERIMENTAL WORK}

\section{A. The Model Properties and Setup -}

The specimens consist of two single bay moment resisting steel frames. The frames are designed by the static analysis approach. They are considered as 3D models, with a story height of $40 \mathrm{~cm}$, the total height of the 2-story frame is 80 $\mathrm{cm}$. Beam and column sections consist of $30 \times 15 \mathrm{~cm}$ and $5 \times 2$ $\mathrm{mm}$ plates. The connections are made directly to plates by bolts. The figure 1 shows the test frames. The mass of each plate is 3000 grams and is directly connected to the columns by bolts. The impacts between two frames are occurring at each level through a contact element. Contact elements consist of two major parts. 


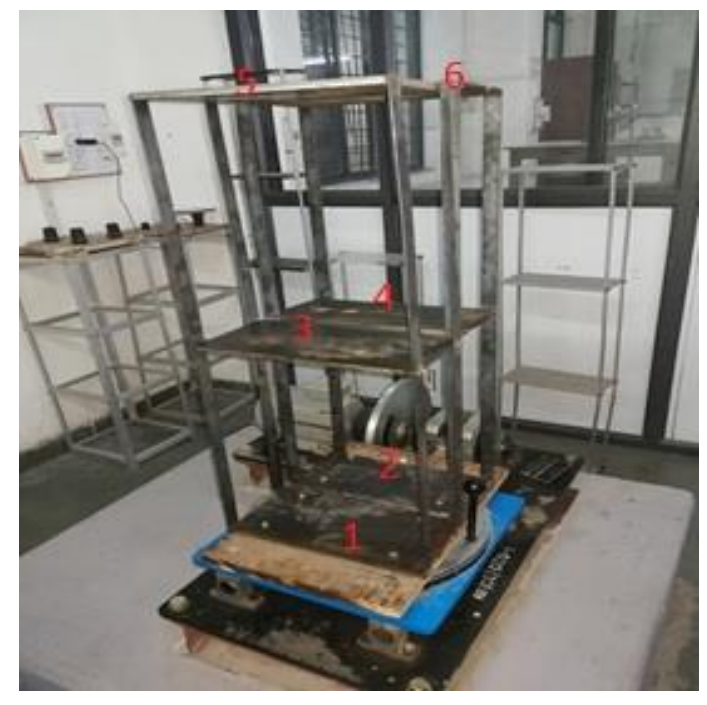

Fig 1. Experimental Model and Sensor System.

\section{B. Shaking Table and Data Acquisition System}

The shake table of Amrutvahini College of engineering has been used to conduct the experiment reported in this study. Shaking table tests have been carried out to investigate the pounding between two steel towers with different structural dynamic properties. The radius of a shake table is $20 \mathrm{~cm}$. The capacity of a shake table is $30 \mathrm{~kg}$.

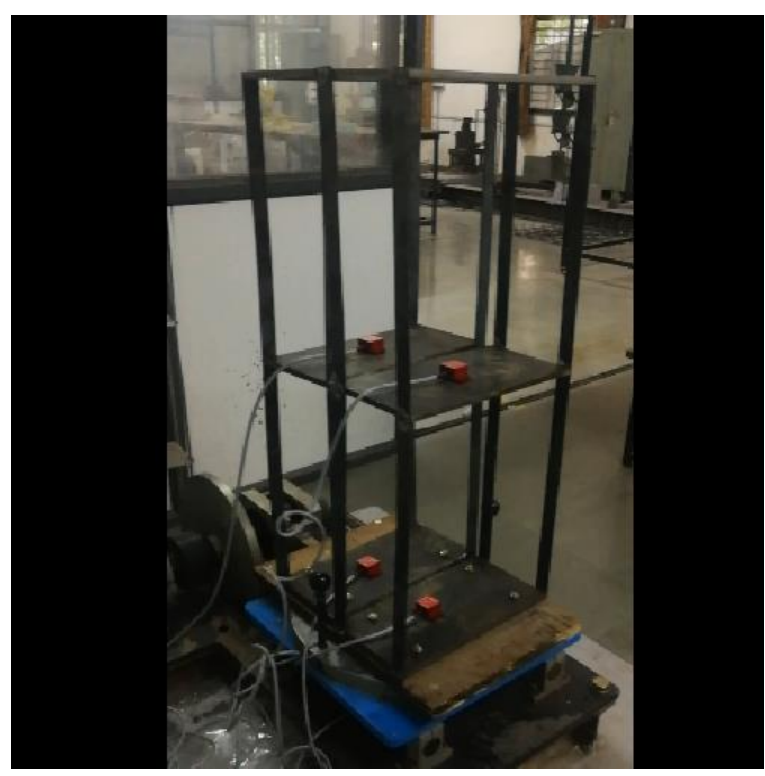

Fig 2. Experimental setup of Model

Both frames are attached to a shake table by using wooden plate. Typical view of whole experimental setup is given by Figure 2.The shaking table is able to apply acceleration, velocity or displacement harmonic excitation by the actuator to the table platform. By giving different frequencies to shake table the interaction of sample frames with shaking table was recorded by ACCMON. The displacements response data were obtained using acceleration sensors. Acceleration Sensors are installed at each floor level. There are 6 sensors were used in these tests. The maximum displacement ranges, the data acquisition system had 6 outputs channels for strain gages and sensors. Sensors give data of the displacement/velocity/acceleration at each floor level as shown in table 1 .

\section{Test Results}

Table 1. Representation of Time History Results

\begin{tabular}{ccccc}
\hline $\begin{array}{c}\text { Frequency } \\
\mathrm{Hz}\end{array}$ & Sensor & $\begin{array}{c}\text { Max } \\
\text { Displacement } \\
\mathrm{mm}\end{array}$ & $\begin{array}{c}\text { Max } \\
\text { Velocity } \\
\mathrm{mm} / \mathrm{s}\end{array}$ & $\begin{array}{c}\text { Acceleration } \\
\mathrm{g}\end{array}$ \\
\hline 2 & 1 & 4.886 & 58.324 & 0.142 \\
\hline & 2 & 8.532 & 101.861 & 0.248 \\
\hline & 3 & 9.427 & 112.54 & 0.274 \\
\hline & 4 & 13.693 & 163.471 & 0.398 \\
\hline 5 & 4.140 & 23.412 & 0.027 \\
\hline 3 & 6 & 21.774 & 123.128 & 0.142 \\
\hline & 1 & 3.359 & 29.543 & 0.053 \\
\hline 2 & 11.216 & 98.663 & 0.177 \\
\hline 3 & 3.929 & 34.560 & 0.062 \\
\hline 4 & 10.646 & 93.647 & 0.168 \\
\hline 4 & 5 & 4.499 & 39.557 & 0.071 \\
\hline & 6 & 19.074 & 167.784 & 0.301 \\
\hline & 1 & 1.380 & 7.804 & 0.009 \\
\hline & 2 & 20.394 & 115.324 & 0.133 \\
\hline & 3 & 1.380 & 7.804 & 0.009 \\
\hline 4 & 6.747 & 38.152 & 0.044 \\
\hline 5 & 17.065 & 203.772 & 0.496 \\
\hline 6 & 23.155 & 276.442 & 0.673 \\
\hline & & & &
\end{tabular}

III. ANALYTICAL WORK

The same model is also prepared in SAP 2000 NL as shown in figure 3. Side view as well as $3 \mathrm{D}$ view of model shown by figure 3 . This software can conduct time history analysis and it has a non-linear gap element suitable for modelling the pounding effect. To test the model the gap between frames, the linear spring gap element was used. Material, masses, dimensions and all elements were defined similarly to the actual values of experimental frame models. Accelerations measured from the shaking table platform at the base level during tests were used as input for the nonlinear time history analyses as ground excitations. To model frames connections, a rigid rod with a rigid connection to each frame was considered. Floor accelerations and displacements are measured as the response parameters in shaking table tests. 


\section{International Journal of Engineering Applied Sciences and Technology, 2019 \\ Vol. 4, Issue 5, ISSN No. 2455-2143, Pages 493-497 \\ Published Online September 2019 in IJEAST (http://www.ijeast.com)}

Tests and analyses results show the importance of frequency content in pounding effects. Results of analyses had a good correlation with experimental results. The damping ratio was assumed as $2 \%$, the same value as obtained in free vibration tests.
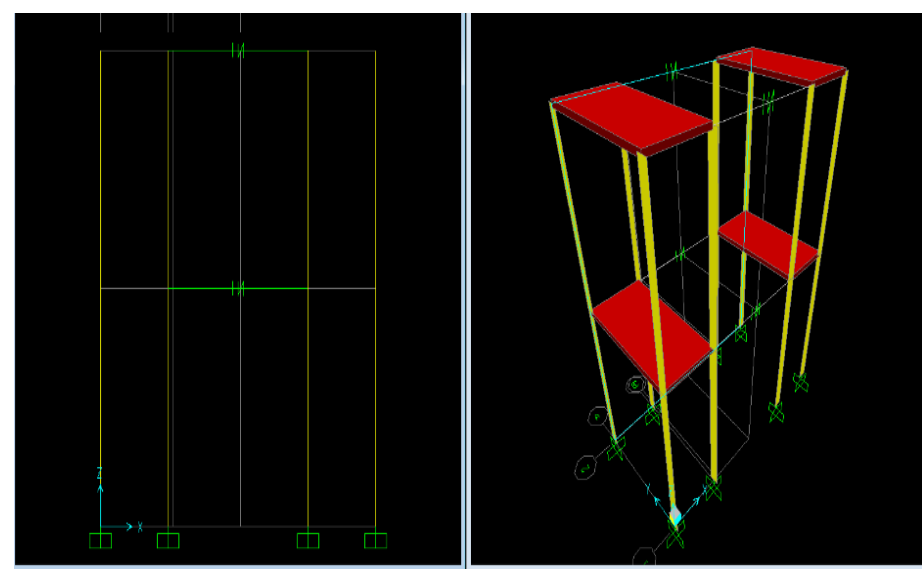

Fig 3. Analytical Model

\section{A. Test Results}

These results are measured in terms of displacement velocity and acceleration at each floor level in analytical investigation. This results are the peak values of time history plots as shown in table 2.

Table 2. Representation of Time History Results

\begin{tabular}{|c|c|c|c|c|}
\hline $\begin{array}{c}\text { Frequency } \\
\mathrm{Hz}\end{array}$ & Sensor & $\begin{array}{c}\text { Max } \\
\text { Displacement } \\
\text { Mm }\end{array}$ & $\begin{array}{c}\text { Max } \\
\text { Velocity } \\
\mathrm{mm} / \mathrm{s} \\
\end{array}$ & $\begin{array}{c}\text { Acceleration } \\
\mathrm{g}\end{array}$ \\
\hline \multirow[t]{6}{*}{2} & 1 & 4.346 & 44.296 & 0.104 \\
\hline & 2 & 7.930 & 89.427 & 0.228 \\
\hline & 3 & 8.877 & 101.44 & 0.242 \\
\hline & 4 & 13.513 & 149.159 & 0.363 \\
\hline & 5 & 3.964 & 17.894 & 0.007 \\
\hline & 6 & 20.682 & 110.009 & 0.110 \\
\hline \multirow[t]{6}{*}{3} & 1 & 3.520 & 22.564 & 0.009 \\
\hline & 2 & 11.543 & 91.415 & 0.132 \\
\hline & 3 & 3.784 & 26.325 & 0.021 \\
\hline & 4 & 10.556 & 87.269 & 0.153 \\
\hline & 5 & 4.312 & 31.723 & 0.040 \\
\hline & 6 & 19.074 & 151.419 & 0.010 \\
\hline \multirow[t]{6}{*}{4} & 1 & 1.429 & 6.048 & 0.001 \\
\hline & 2 & 19.178 & 103.614 & 0.098 \\
\hline & 3 & 1.256 & 4.218 & 0.002 \\
\hline & 4 & 6.747 & 46.201 & 0.022 \\
\hline & 5 & 17.671 & 184.674 & 0.429 \\
\hline & 6 & 22.973 & 226.256 & 0.639 \\
\hline
\end{tabular}

\section{COMPARISON BETWEEN EXPERIMENTAL AND NUMERICAL STUDIED}

From graph 1, 2, 3 it is observed that in the pounding cases, the differences between measured acceleration and velocity in the tests and in the analysis responses were high, although there were resemblances in their trends. However, for displacement responses, there was more similarity between tests and analyses results. In the case of harmonic excitation over shake table, the peak acceleration from experiments for all cases was more than what obtained from the analyses. It was mainly observed in the 3rd floor of frames, which was the location of pounding. In both experiments and analyses, the differences between acceleration velocity and displacement responses for the case with connections at one level or at two levels were negligible. Graph 4,5,6,7 shows that time history analysis of joint 3 and 5 in experimental and analytical study. And graph 8 and 9 shows pounding force occurred at each floor level.

Graph 1. Comparison between displacement in Numerical and Experimental studies

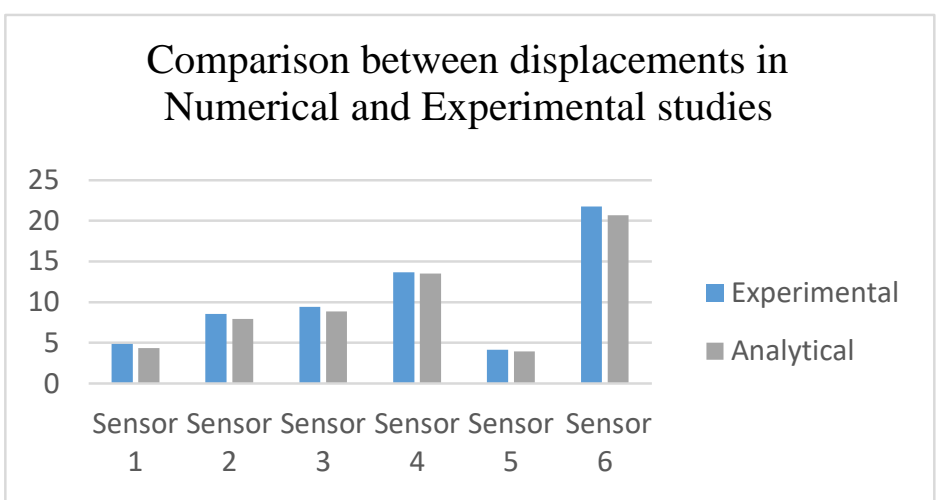

Graph 2. Comparison between Velocity in Numerical and Experimental studies

Comparison between velocity in Numerical and Experimental studies

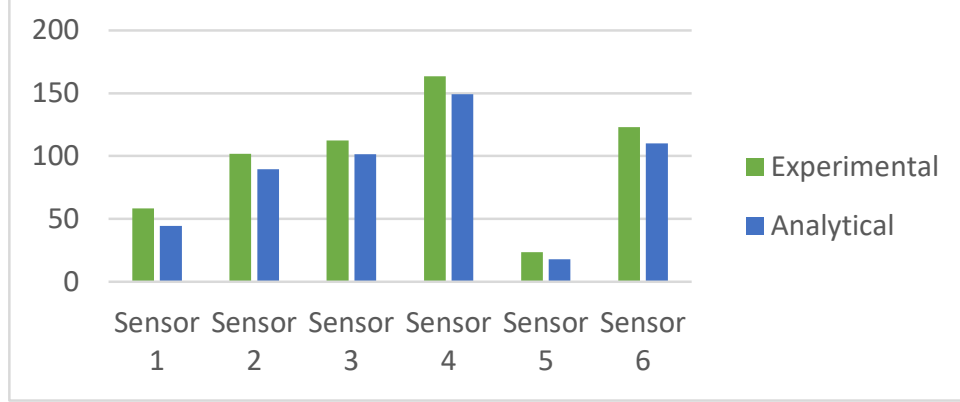




\section{International Journal of Engineering Applied Sciences and Technology, 2019 \\ Vol. 4, Issue 5, ISSN No. 2455-2143, Pages 493-497 \\ Published Online September 2019 in IJEAST (http://www.ijeast.com)}

Graph 3. Comparison between displacement in Numerical and Experimental studies

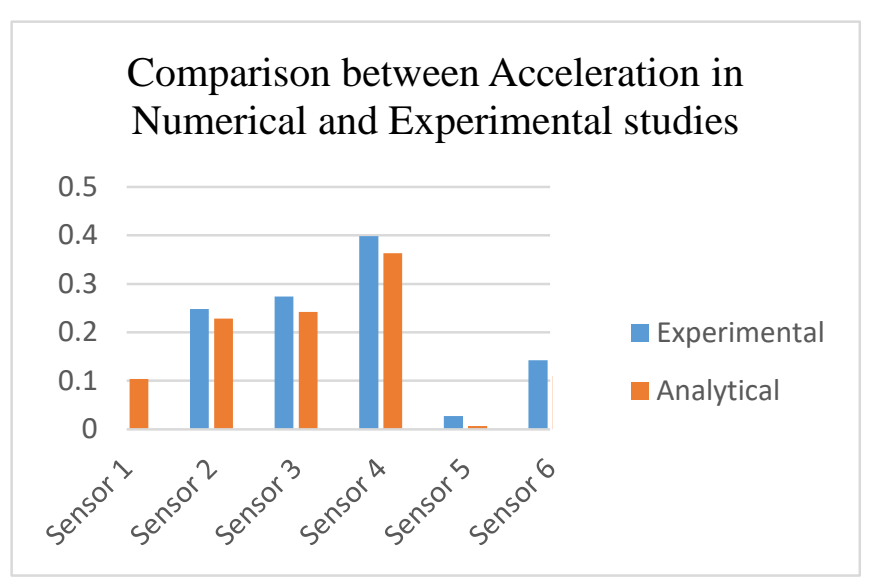

Graph 4. Time history Analysis of Sensor 3 in Experimental study

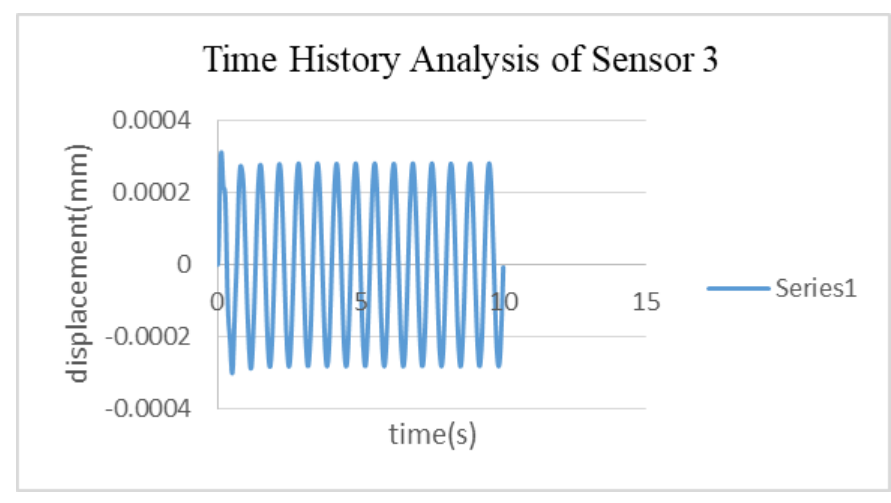

Graph 5. Time history Analysis of Sensor 3 in Analytical Study

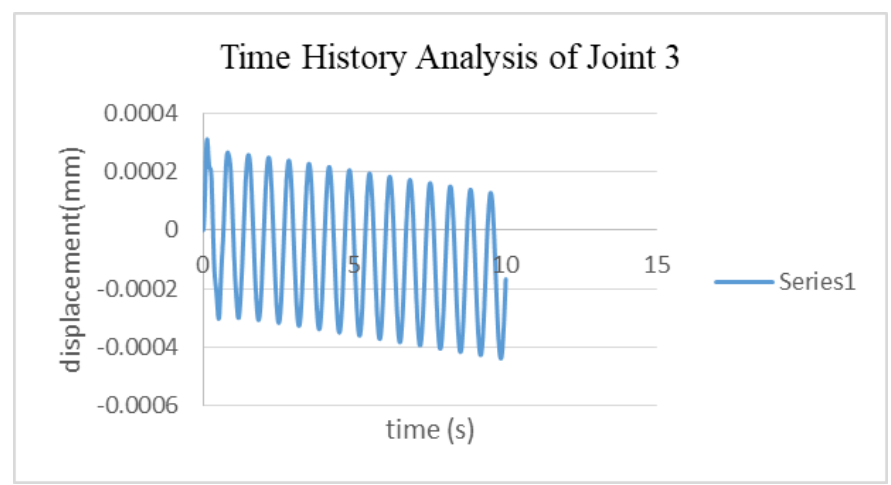

Graph 6. Time history Analysis of Sensor 5 in Experimental study

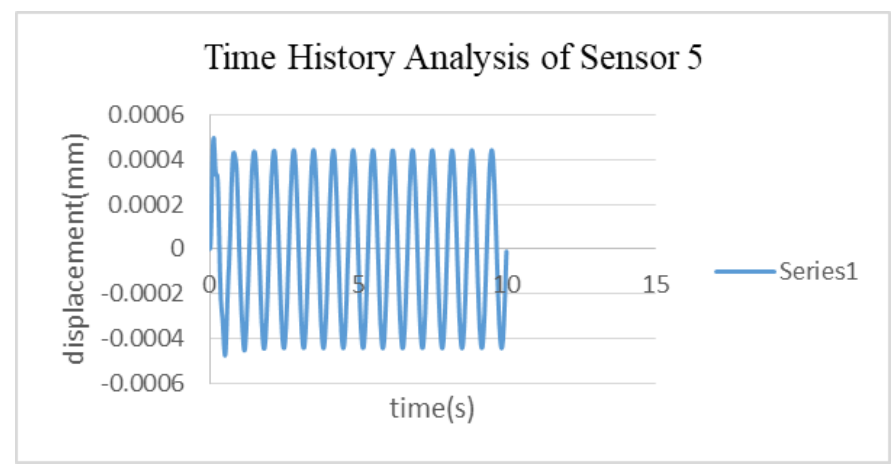

Graph 7. Time history Analysis of Sensor 5 in Analytical Study

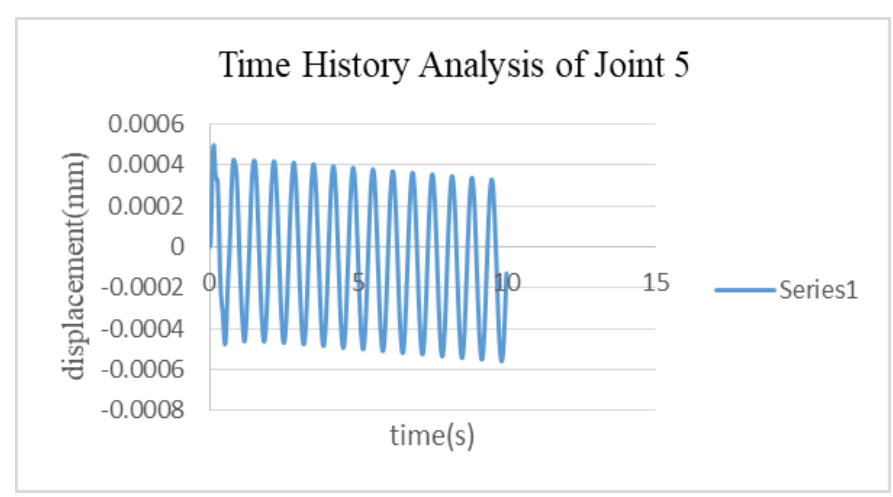

Graph 8. Pounding Force at Top floor level in Analytical Study

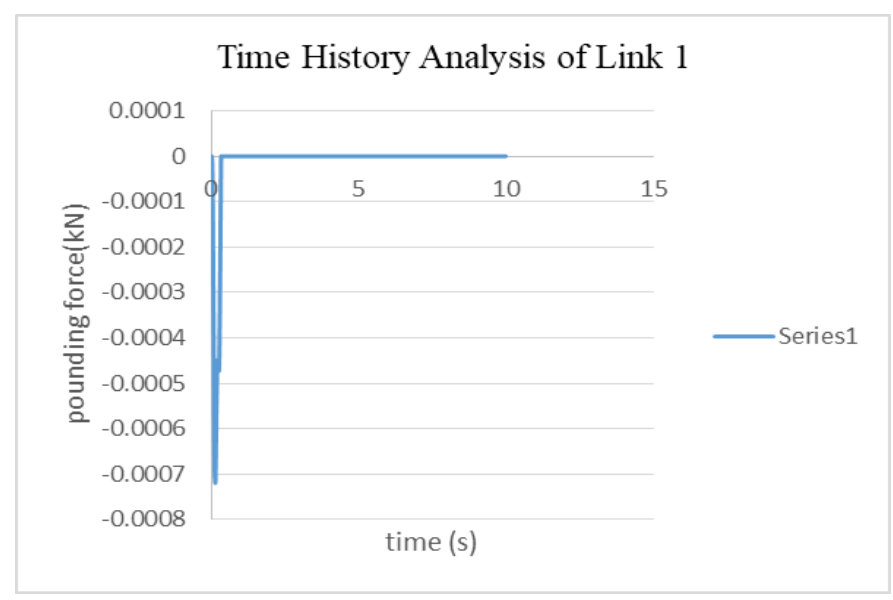




\section{International Journal of Engineering Applied Sciences and Technology, 2019 \\ Vol. 4, Issue 5, ISSN No. 2455-2143, Pages 493-497 \\ Published Online September 2019 in IJEAST (http://www.ijeast.com)}

Graph 9. Pounding Force at First floor level in Analytical Study

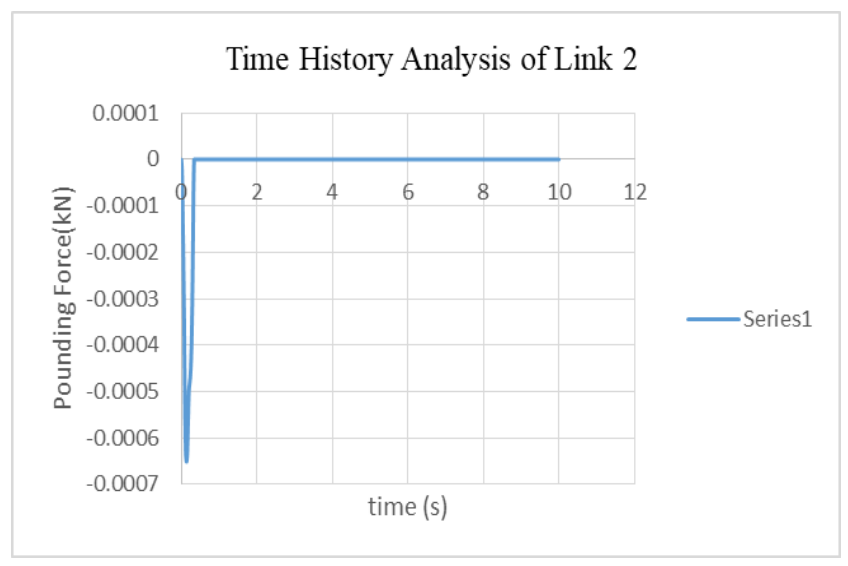

\section{CONCLUSION}

From this information, we get that the experimental results and software results are in good agreement. In the presence of pounding the acceleration at the all floor levels are significantly increases which result in large displacements at the top floor levels. Which may also increase the base shear, base moments of the structures. In individual members of an adjacent structure in SAP2000NL, the axial force, shear force and bending moments may also increase due to the effect of pounding. The amplification of internal force quantity depends upon the gap and adjacent building structural properties. The analyses results were very sensitive to the stiffness of the impact element.

\section{REFERENCE}

[1] Abdullah M.M., Hanif J.H., Richardson A. and Sobanjo J. (2001). "Use of a shared tuned mass damper (STMD) to reduce vibration and pounding in adjacent structures", Earthquake Engineering and Structural Dynamics, Vol. 30,(pp. 1185-1201).

[2] Anagnostopoulos S.A. (1995)."Earthquake induced pounding: state of the art", Proceedings of the 10th European Conference on Earthquake Engineering, (pp. 897-905).

[3] Anagnostopoulos, S.A. (1996). "Building pounding reexamined: how serious a problem is it?" Proceedings of 11th World Conference on Earthquake Engineering, Mexico, (paper No. 2108).

[4] Anagnostopoulos S.A. and Spiliopouls K.V. (1992). "An investigation of earthquake induced pounding between adjacent buildings", Earthquake Engineering and Structural Dynamics, Vol. 21, (pp. 289-302).

[5] Bertero V.V. (1996). "Implications of observed pounding of buildings on seismic code regulations", Proceedings of 11th World Conference on Earthquake Engineering, Mexico, (Paper No. 2102).

[6] Blondet M. and Esparza C. (1988). "Analysis of shaking table structure interaction effects during seismic simulation tests", Earthquake Engineering and Structural Dynamics, Vol. 16, No. 4, (pp. 473-490).

[7] Structural Analysis Program (2009) SAP User's Manual .Computers and Structures Inc,Berkeley.

[8] Chau K.T., Wei X.X., Guo X. and Shen C.Y. (2003). "Experimental and theoretical simulations of seismic poundings between two adjacent structures", Earthquake Engineering and Structural Dynamics, Vol. 32, (pp. 537554).

[9] Chau K.T. and Wei X.X. (2001). "Pounding of structures modelled as non-linear impacts of two oscillators", Earthquake Engineering and Structural Dynamics, Vol. 30, (pp. 633-651).

[10] Conoscente J.P., Hamburger R.O. and Johnson J.J. (1992). "Dynamic analysis of impacting structural systems", Proceedings of 10th world conference on earthquake engineering, (pp. 3899-3903).

[11] Coias e.V., Lourenco P.B., Ramos L.F. and Mesquita C.G. (2001). "Accounting for the block effect in structural interventions in Lisbon's old pombaline downtown buildings", Historical Constructions, Guimaraes, (pp. 943-952).

[12] Davis R.O. (1992). "Pounding of buildings modeled by an impact oscillator", Earthquake Engineering and Structural Dynamics, Vol. 21, (pp. 253-274). 